\title{
AVALIAÇÃO DA POSTURA CORPORAL DOS TRABALHADORES DE ENFERMAGEM NA MOVIMENTAÇÃO DE PACIENTES ACAMADOS*
}

\author{
EVALUATION OF THE CORPORAL POSTURE OF THE NURSING WORKERS \\ IN THE MOVEMENT OF PATIENTS IN BED.
}

\author{
Elenita Zanon ** \\ Maria Helena Palucci Marziale ***
}

\begin{abstract}
ZANON, E.; MARZIALE, M. H. P. Avaliação da postúra corporal dos trabalhadores de enfermagem na movimentação de
\end{abstract} pacientes acamados Rev.Esc.Enf.USP, v. 34, n. 1, p. 26-36, mar. 2000.

\section{RESUMO}

A movimentação de pacientes no leito, é um procedimento que requer grande esforço físico e utilização de boa mecânica corporal pelo pessoal de enfermagem, afim de prevenir-lhes problemas de dores nas costas. Reconhecendo a importância da movimentação e posicionamento, para promover segurança e conforto ao paciente, e diante das queixas dos profissionais, descritas na literatura, este trabalho tem por objetivos: identificar e analisar as posturas assumidas pelos trabalhadores de enfermagem e, identificar as facilidades e dificuldades encontradas durante a execução da referida atividade. Através da técnica de observação direta foram filmados, através de video tape, trinta procedimentos de movimentação de paciente no leito executados por trabalhadores de enfermagem de uma clínica ortopédica de um hospital universitário. Os resultados evidenciaram que os trinta procedimentos foram executados ao longo de 197,41 minutos e que a postura corporal mais freqüentemente assumida foi coluna inclinada, braço com cotovelo abaixo da bancada, pernas extensão (53,76\%). De acordo com os principios da mecânica corporal e da ergonomia, tal postura é considerada penosa ao homem, devido às agressões músculo-esqueléticas e à sobrecarga física que acarreta. Os trabalhadores apontaram os aspectos: pequeno espaço (58,82\%), elevada carga física (52,94\%) e falta de pessoal (47,06\%) como as principais dificuldades encontradas na execução da movimentação de paciente no leito, corroborando com os achados da literatura, caracterizando essa atividade como penosa, também apontaram que o uso da técnica adequada para movimentar o paciente (35,29\%), o uso do lençol (35,29\%) e o espaço adequado da enfermaria (23,52\%), como aspectos que facilitariam a execução do procedimento.

PALAVRAS-CHAVE: Enfermagem. Trabalhadores. Ergonomia. Dor nas costas. Postura.

\begin{abstract}
The patients' movement in bed, is a procedure that demand great physical effort and use of good corporal mechanics for the nursing personnel, relative of preventing them back pain problems. Recognizing the importance of the movement and positioning, to promote safety and comfort to the patient, and before the professionals' complaints, described in the literature, this work has for objectives: to identify and analyzer the postures assumed by the nursing workers and identify the means and difficulties found during the execution of the referred activity. Through the technique of direct observation they were filmed, through videotapes, thirty procedures of patient's movement in the bed executed by nursing workers of an orthopedic clinic of an university hospital. The results evidence that the thirty procedures were executed along 197,41 minutes and that the corporal postures more frequently assumed they were, in respect to back, arms and legs, back inclined/arms with elbow down of row of seats/legs extension (53,76\%). In agreement with the beginnings of the corporal mechanics and of the ergonomics, such postures are considered painful to the man, due to the muscle-skeletal aggressions and to the physical overload that they cart. The workers aimed the aspects little space (58,82\%), physical load (52,94\%) and absence of the personal (47,06\%), as the main difficulties found in the execution of patient's movement in the bed, corroborating with the discoveries of the literature, characterizing that activity as painful. They pointed: the adequate technique (36,29\%), used of sheet (35,29\%) and space adequate (23,52\%), as aspects that would facilitate the execution of the procedure.
\end{abstract}

KEYWORDS: Nursing. Workers. Ergonomics. Back pain. Posture.

Trabalho apresentado no VI Colóquio Pan-Americano de Enfermagem. Ribeirão Preto -SP, 1998

Aluna de Graduação da Escola de Enfermagem de Ribeirão Preto da Universidade de São Paulo, bolsista FAPESP.

Professor Doutor junto ao Departamento de EGE da Escola de Enfermagem de Ribeirão Preto da Universidade de São Paulo. 


\section{INTRODUÇÃO}

As condições de trabalho do pessoal de enfermagem em hospitais, cada vez mais, vêm sendo contempladas como objetos de pesquisas devido aos riscos que o ambiente oferece e aos aspectos penosos das atividades peculiares à assistências de enfermagem, entre os quais encontram-se aqueles relacionados a movimentação e posicionamento de pacientes no leito.

O posicionamento do paciente no leito é uma intervenção executada por enfermeiros, técnicos e auxiliares de enfermagem, com vistas a prevenir o processo degenerativo da pele, músculos, ossos, articulações e promover conforto e segurança ao paciente acamado (KOZIER, ERB, OLIVERI, 1991).

Mudanças freqüentes de posição ajudam a evitar desconforto muscular e pressão desproporcional que resultam em ulceras de decúbito, danos a nervos superficiais, vasos sangüíneos e contraturas, mantém ainda o tônus muscular e estimulam reflexos posturais (SORENSEN; LUCKMANN, 1994).

A movimentação de pacientes no leito, é um procedimento que requer grande esforço físico e utilização adequada da mecânica corporal pelo pessoal de enfermagem (OGUISSO; SCHIMIDT,1984).

MARZIALE (1995), ao analisar as condições ergonômicas da situação de trabalho do pessoal de enfermagem, em uma unidade de internação hospitalar constatou que a execução da atividade de movimentação de pacientes acamados foi apontada pelos trabalhadores de enfermagem como a atividade mais desgastante fisicamente sobretudo devido a inadequação dos mobiliários e recursos instrumentais utilizados e as posturas corporais assumidas pelos trabalhadores de enfermagem.

Estudos sobre os esforços na execução de atividades de enfermagem têm sido desenvolvidos em decorrência do elevado dispêndio de força muscular e gasto excessivo de energia fisica empreendidos na realização de atividades como levantamento, manuseio e transporte de pacientes e materiais, os quais tem ocasionado problemas posturais e fadiga nos trabalhadores de enfermagem (ESTRYN-BEHAR, 1980; TREUREAU, 1980).

Dentre as queixas relacionadas à saúde dos trabalhadores de enfermagem, as cervicodorsolombalgias tem sido as de maior prevalência, ocasionadas sobretudo, devido ao grande número de posicionamento e levantamento de pacientes por esses profissionais, como mostram (REIS, 1986; AQUINO et al., 1993).

O problema das cervicodorsolombalgias entre os trabalhadores de enfermagem vem sendo constantemente detectada. Os estudos realizados por CUST et al. (1972); JENSEN, (1987) e ALEXANDRE (1993) elucidam entre os fatores que predispõem a dores nas costas a adoção de posturas inadequadas na execução das atividades desenvolvidas por esses trabalhadores.
Os estudos realizados por REIS(1986); ALEXANDRE et al. (1992); ALEXANDRE; ANGERAMI (1995), apontam que, as algias da coluna no pessoal de enfermagem são atribuídas a vários fatores, individuais e profissionais, tais como: espaço físico inadequado, equipamentos em más condições de uso devido à manutenção insatisfatória ou inexistente, quadro de funcionários reduzido e dupla jornada de trabalho.

ALEXANDRE; ANGERAMI (1995), descrevem ainda como fator predisponente às cervicodorsolombalgias o fato da equipe de enfermagem ser composta quase que totalmente por mulheres, as quais, além de suas atividades profissionais, são também responsáveis por tarefas domésticas, que demandam de esforço fisico considerável.

MARZIALE et al. (1991), descrevem que os profissionais de enfermagem adotam determinadas posturas, por tempo prolongado, o que poderia estar-lhes agravando os problemas de cervicodorsolombalgias.

Outras constantes no que diz respeito aos problemas encontrados por estudiosos são os equipamentos em condições de manutenção insatisfatórias, (vários estudos apontam que uma grande queixa do trabalhador de enfermagem são aquelas que dizem respeito à equipamentos que não receberam lubrificação tais como: rodas de maca ou cadeira, manivelas de camas), a diferença de nível de altura entre camas e macas ou entre cadeiras de rodas e cadeiras de banho e a falta de utilização de recursos tecnológicos quais sejam: elevadores de pacientes, camas e macas de altura ajustáveis (REIS, 1986; ALEXANDRE, 1993; ALEXANDRE; ANGERAMI, 1993; MARZIALE, 1995).

A inadequação dos mobiliários e espaços, associada a não utilização da boa postura pelos trabalhadores de enfermagem têm sido responsáveis por injúrias músculo-esqueléticas e perda de tempo de serviço. ENGELS et al. (1994), concluíram que o pessoal de enfermagem chega a assumir cerca de $20 \%$ de seu tempo de trabalho no que chamam de "posturas pobres", às quais representam sobrecarga para estes trabalhadores, acarretando um maior dispêndio de esforço físico e maior probabilidade de danos no sistema músculo-esquelético.

Segundo REIS (1986) é importante enfatizar a necessidade de adoção de posturas corretas na execução dos procedimentos técnicos desenvolvidos pelos elementos componentes da equipe de enfermagem durante a formação desses profissionais.

ALEXANDRE et al. (1992) referem que uma maneira para minimizar a falta de conhecimento em relação a estes conceitos pode ser buscado através da promoção de cursos e treinamento em serviço.

A ergonomia, ciência que estuda a interação entre o homem e seu trabalho, tem possibilitado estudar, analisar e compreender o conjunto de fatores que proporcionam ou agravam as cervicodorsolombalgias na 
equipe de enfermagem, pois os fatores que contribuem para produzir lesões na coluna, geralmente, estão ligados aos elementos que compõe o ambiente de trabalho (ALEXANDRE, 1993).

\section{JUSTIFICATIVA DO ESTUDO}

Reconhecendo a importância do posicionamento adequado do paciente no leito para a promoção de segurança e conforto ao paciente e diante das queixas descritas na literatura sobre as penosidades que a execução desta atividade vem causando aos trabalhadores de enfermagem, o estudo ora apresentado busca analisar a adoção das posturas assumidas pelos trabalhadores de enfermagem na movimentação de pacientes.

\section{OBJETIVOS}

- Identificar as posturas corporais assumidas pelos trabalhadores de enfermagem na execução da atividade de movimentação de pacientes acamados;

- O Identificar as facilidades e dificuldades encontradas pelos trabalhadores de enfermagem na execução da atividade de movimentação de pacientes acamados.

\section{MATERIAL E MÉTODO}

- $\mathbf{O}$ Local: o estudo foi realizado junto a unidade de internação da clínica ortopédica de um hospital universitário do interior do estado de São Paulo.

- População e Amostra: A população da unidade estudada era composta por trinta e sete trabalhadores distribuídos nas seguintes categorias: dez enfermeiros, vinte e seis auxiliares de enfermagem e um atendente de enfermagem.

A amostra foi constituída por dezessete trabalhadores de enfermagem (dois enfermeiros e quinze auxiliares de enfermagem) que aceitaram participar da pesquisa e que executaram o procedimento de movimentação de paciente no leito durante a execução dos cuidados de banho no leito e arrumação de cama durante o período destinado à coleta de dados, qual seja : 13/11/97 a 14/01/98. Pela técnica de observação direta, os dezessete trabalhadores de enfermagem executaram no período de coleta de dados trinta procedimentos de movimentação de pacientes acamados, os quais foram gravados em um total de 197,41 minutos de filmagem, em fitas de vídeo.

- O Aspectos Éticos: o projeto de pesquisa foi enviado ao comitê de regulamentação e normas éticas do hospital estudado. Uma vez obtida a aprovação para a realização da pesquisa os trabalhadores foram orientados individualmente e aceitaram participar da mesma. Os pacientes também foram orientados e esclarecidos sobre a filmagem do procedimento consentindo voluntariamente participar da amostra.
Foram preservados os aspectos descritos no Código de Ética dos Profissionais de Enfermagem, publicado pelo Conselho Federal de Enfermagem (1993).

\section{PROCEDIMENTOS DE EXECUÇÃO DA PESQUISA}

- Revisão da Literatura: Realizada revisão da literatura sobre a temática em questão através de consulta aos bancos de dados Lilacs e Medline em período retrospectivo de dez anos (1997 a 1987);

- Validação do Instrumento de Coleta de Dados: Realizada validação do roteiro de entrevista utilizado para a coleta de dados. O referido instrumento, contendo perguntas abertas e fechadas, teve por objetivo obter informações sobre as facilidades e dificuldades percebidas pelos trabalhadores de enfermagem na execução da atividade de movimentação de pacientes no leito. $O$ instrumento foi apreciado por três pesquisadores em relação a seu conteúdo, clareza e objetividade, sendo acatadas as sugestões feitas e realizados os ajustes necessários.

- Treinamento para Coleta de Dados: Realizado treinamento da autora quanto a técnica de filmagem para o registro em vídeo das posturas adotadas pelos trabalhadores de enfermagem na movimentação de pacientes no leito e quanto à técnica de entrevista.

As posturas foram categorizadas em relação ao conjunto: posição do dorso, braços e pernas, considerando-se boa postura aquela onde foi adotada o conjunto: dorso ereto, braços fletidos com cotovelos na altura da bancada ou até cinco centímetros acima ou abaixo desta e pernas flexionadas andando ou parada.

Outras posições fora as descritas foram categorizadas como má postura.

- Coleta de dados: Realizada coleta de dados no periodo de 13/11/97 a 14/01/98, durante o plantão da manhã.

Foram entrevistados os 17 trabalhadores de enfermagem que executaram 30 procedimentos de movimentação de pacientes no leito. Cabe ressaltar que alguns trabalhadores executaram mais de um procedimento, sendo a entrevista realizada, nesses casos, uma única vez. As entrevistas foram realizadas logo após o término da execução da atividade, sendo que as mesmas foram realizadas no posto de enfermagem da unidade.

\section{RESULTADOS E DISCUSSÃO}

Os resultados encontram-se apresentados através de tabelas e gráficos e analisados com base em cálculos percentuais.

Dos 17 trabalhadores que compuseram a amostra, nove eram pertencentes ao sexo feminino $(52,9 \%)$ e oito ao masculino $(47,1 \%)$, apresentando 
idades compreendidas entre 30 e 65 anos, sendo que $52,9 \%$ dos sujeitos apresentaram idades de 30 a 40 anos. Quanto ao estado civil, $47,1 \%$ dos trabalhadores eram solteiros, $35,3 \%$ casados e $17,6 \%$ eram divorciados ou desquitados.
Através da tabela 1 são apresentados os dados de distribuição da amostra relacionados ao sexo, idade e estado civil.

Tabela 1- Distribuição dos sujeitos da amostra face às características sexo, idade e estado civil (n=17). Ribeirão Preto, 1998.

\begin{tabular}{c|c|c|c}
\hline \multirow{2}{*}{ Variáveis } & Caracteristicas & \multicolumn{2}{|c}{ Freqüências } \\
\cline { 2 - 4 } & Feminino & 9 & Percentual \\
\hline \multirow{3}{*}{ Sexo } & Masculino & 8 & $52,9 \%$ \\
\cline { 2 - 4 } & Total & 17 & $47,1 \%$ \\
\cline { 2 - 4 } & $30-40$ & 9 & $100 \%$ \\
\cline { 2 - 4 } & $40-50$ & 6 & $32,9 \%$ \\
\cline { 2 - 4 } & $50-60$ & 1 & $5,3 \%$ \\
\cline { 2 - 4 } & $60-$ & 1 & $5,9 \%$ \\
\cline { 2 - 4 } & Total & 17 & $100 \%$ \\
\hline \multirow{3}{*}{ Estado Civil } & Solteiro & 8 & $37,1 \%$ \\
& Casado & 6 & $17,3 \%$ \\
\cline { 2 - 4 } & Outros & 3 & $100 \%$ \\
\cline { 2 - 4 } & Total & 17 & \\
\cline { 2 - 4 } & & & \\
\hline
\end{tabular}

Segundo a descrição do perfil da força de trabalho na enfermagem, publicada pelo Conselho Federal de Enfermagem (CONSELHO FEDERAL DE ENFERMAGEM, 1985), cerca de 98\% dos trabalhadores de enfermagem brasileiros da época, eram pertencentes ao sexo feminino, e com idade mais incidente na faixa etária de 20 a 40 anos e entre 40,4\% e $56,6 \%$ dos trabalhadores eram casados.

Os dados da amostra estudada, revelam que $52,9 \%$ dos trabalhadores pertencem ao sexo feminino, $52,9 \%$ possuem idade inferior a 40 anos e apenas $35,3 \%$ dos trabalhadores são casados, indicando peculiaridades que distanciam do perfil geral dos trabalhadores de enfermagem, pois tais achados podem estar relacionados ao fato da unidade de ortopedia estar dividida em duas alas, uma para internação de pacientes do sexo feminino e outra para os de sexo masculino, e ser dado preferência, quando da contratação de pessoal, para alocar trabalhadores masculinos junto à ala de internação masculina e de trabalhadoras junto a ala de internação feminina.

Em relação ao tempo de trabalho na unidade de ortopedia, podemos observar através da figura 1 , a sua distribuição.

Figura 1- Distribuição do tempo de trabalho dos trabalhadores de enfermagem junto a unidade de internação de ortopedia de um hospital universitário (n=17). Ribeirão Preto, 1998.

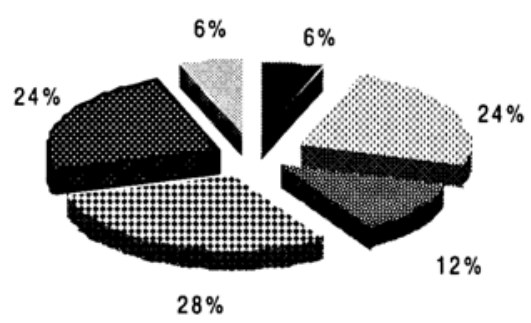

Através da figura 1 observamos que quatro $(23,5 \%)$ trabalhadores de enfermagem apresentam tempo de serviço na unidade em período compreendido entre 20 a 30 anos, cinco $(29,4 \%)$ entre 10 e 20 anos, seis $(35,4 \%)$ entre 1 e 10 anos, sendo que apenas um $(5,9 \%)$ trabalhador apresenta menos de 1 ano de trabalho na unidade. Dos 17 trabalhadores que compuseram a amostra $14(82,4 \%)$ possuem

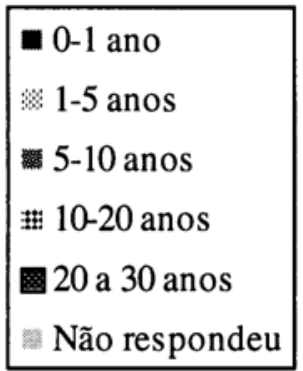

outra atividade laboral sendo que 13 (76,47\%) executam atividades na enfermagem, e um $(5,93 \%)$ é cabeleireiro.

Através da tabela 2 apresentamos a opinião dos 14 trabalhadores que referiram possuir outra atividade laboral, em relação a postura adotada e ao esforço físico dispendido para executar as atividades que normalmente realizam na segunda jornada. 
Tabela 2- Distribuição das respostas emitidas pelos sujeitos da amostra segundo o esforço físico realizado na execução das atividades laborais no segundo emprego (n=14). Ribeirão Preto, 1998.

\begin{tabular}{l|c|c|c|c|c|c}
\hline \multirow{2}{*}{$\begin{array}{l}\text { Resforço } \\
\text { Respostas }\end{array}$} & \multicolumn{2}{|c|}{ SIM } & \multicolumn{2}{c}{ NÃO } & \multicolumn{2}{c}{ TOTAL } \\
\cline { 2 - 7 } & Número & Percentual & Número & Percentual & Número & Percentual \\
\hline Empreender esforço físico & 13 & $92.9 \%$ & 1 & $7.1 \%$ & 14 & $100 \%$ \\
\hline Inclinar a coluna & 13 & $92.9 \%$ & 1 & $7.1 \%$ & 14 & $100 \%$ \\
\hline Carregar peso & 12 & $85.7 \%$ & 2 & $14.3 \%$ & 14 & $100 \%$ \\
\hline Torcer a coluna & 12 & $85.7 \%$ & 2 & $14.3 \%$ & 14 & $100 \%$ \\
\hline $\begin{array}{l}\text { Estirar a coluna } \\
\text { Flexionar a coluna várias } \\
\text { vezes }\end{array}$ & 12 & $85.7 \%$ & 2 & $14.3 \%$ & 14 & $100 \%$ \\
\hline
\end{tabular}

Cabe ressaltar que $92,9 \%$ dos trabalhadores apontaram a necessidade de empregar esforço físico e adoção da postura de inclinar a coluna para a execução das atividades, $85,7 \%$ dos sujeitos referiram a necessidade de torcer, estirar e flexionar várias vezes a coluna e carregar peso. Tais informações sugerem que as atividades executadas no segundo emprego dos trabalhadores de enfermagem podem lhes estar ocasionando sobrecarga física e consequentemente podem estar prejudicando a saúde desses trabalhadores.

Dos sujeitos da amostra, 70,6\% (onze trabalhadores) referiram executar atividades domésticas além das laborais, fato que nos sugere uma segunda ou terceira jornada de trabalho e aumento ainda maior da sobrecarga fisica; através da tabela 3 são descritas as opiniões deste trabalhadores em relação às atividades domésticas que realizam.

Tabela 3- Distribuição das opiniões emitidas pelos trabalhadores de enfermagem da unidade estudada e que referiram realizar atividades domésticas (n=11). Ribeirão Preto, 1998.

\begin{tabular}{|l|c|c|c|c|c|r}
\hline \multirow{2}{*}{ Esforço } & \multicolumn{2}{c|}{ SIM } & \multicolumn{2}{c|}{ NÃO } & \multicolumn{2}{c}{ TOTAL } \\
\cline { 2 - 7 } & \multirow{2}{*}{ Número } & Percentual & \multirow{2}{*}{ Número } & Percentual & Número & Percentual \\
\hline Empreender esforço fisico & 9 & $81,8 \%$ & 2 & $18,2 \%$ & 11 & $100 \%$ \\
\hline Inclinar a coluna & 10 & $90,9 \%$ & 1 & $9,1 \%$ & 11 & $100 \%$ \\
\hline Carregar peso & 8 & $72,7 \%$ & 3 & $27,3 \%$ & 11 & $100 \%$ \\
\hline Torcera a coluna & 7 & $63,6 \%$ & 4 & $36,4 \%$ & 11 & $100 \%$ \\
\hline Estirara coluna & 9 & $81,8 \%$ & 2 & $18,2 \%$ & 11 & $100 \%$ \\
\hline Flexionar a coluna várias & 8 & $72,7 \%$ & 3 & $27,3 \%$ & 11 & $100 \%$ \\
\hline
\end{tabular}

Como mostra a tabela 3 grande parte dos trabalhadores que executam atividades domésticas apontam a necessidade de empregar esforço físico e adotar posturas inadequadas para a realização de tais tarefas, dados estes que vêm corrobar com ALEXANDRE; ANGERAMI (1993), quando descrevem as tarefas domésticas como um fator agravante no aumento de esforço fisico do pessoal de enfermagem.

ALEXANDRE (1993) apresenta em seu estudo que determinadas posturas e movimentações adotadas por um trabalhador repetidamente, durante anos, pode afetar a musculatura e constituição ósseo-articular do mesmo, principalmente a da coluna e dos membros, resultando, a curto prazo em dores e podendo a longo prazo resultar em lesões permanentes e deformidades. Devido ao fato dessas lesões aparecerem lentamente ou serem de efeitos tardios, acabam por dificultar ou impedir que o trabalhador estabeleça a relação causa/efeito, entre os sintomas e as atividades exercidas. Quanto ao estado de saúde, apenas cinco $(29,4 \%)$ trabalhadores, referiram possuir problemas de saúde. Através da figura 2 são apresentados os problemas de saúde que os acometem. 
Figura 2- Distribuição dos problemas de saúde que acometem cinco trabalhadores de enfermagem da amostra estudada ( $\mathrm{n}=5)$. Ribeirão Preto, 1998.

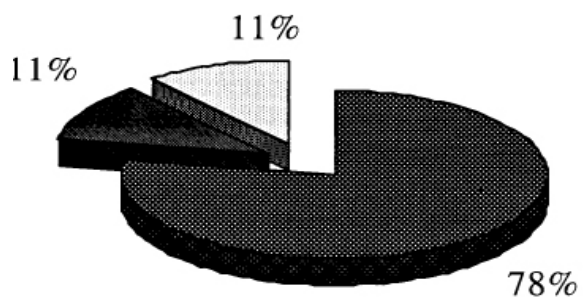

\author{
Problemas ligados ao \\ Sistema Músculo \\ Esquelético \\ Sistema Cardio-vacular
}

$\square$ Sistema Endócrino
Dos cinco trabalhadores que referiram problemas de saúde encontramos, dez diagnósticos médicos, sendo que destes, sete estão relacionados com problemas ligados ao sistema músculo esquelético, dois relacionados ao sistema cardiovascular (Hipertensão e Prolapso Mitral) e um devido a problemas no sistema endócrino (Diabetes Melitus).

Dos 17 trabalhadores de enfermagem que participaram da amostra estudada, sete (63.6\%) referiram afastamento do serviço por problemas ligados ao sistema músculo esquelético.
Dentre as várias atividades executadas pelos trabalhadores de enfermagem optamos em identificar o esforço físico dispendido através de adoção de postura inadequada na atividade de movimentação de paciente acamado.

Através do quadro 1 apresentamos as opiniões emitidas pelos trabalhadores de enfermagem em relação aos fatores que facilitam e os que dificultam a execução da atividade de movimentação de paciente. Ressaltamos que devido ao fato de se tratar de uma pergunta aberta, os trabalhadores puderam emitir mais de uma opinião.

Quadro 1 - Opinião dos trabalhadores de enfermagem segundo os fatores que facilitam e os que dificultam a execução da atividade de movimentação de paciente no leito, sendo os mesmos puderam emitir mais de uma opinião (n=17). Ribeirão Preto, 1998.

\begin{tabular}{|c|c|c|c|}
\hline \multicolumn{2}{|c|}{ Opinião dos trabalhadores } & Número de trabalhadores & $\%$ \\
\hline \multirow{8}{*}{\begin{tabular}{|c|} 
Fatores que \\
facilitam a \\
execução da \\
atividade de \\
movimentação de \\
pacientes no leito
\end{tabular}} & Usar técnica apropriada & 9 & $52.94 \%$ \\
\hline & Usar Lençol & 6 & $35.29 \%$ \\
\hline & Espaço Adequado & 4 & $23.52 \%$ \\
\hline & Mais de uma pessoa & 3 & $17.64 \%$ \\
\hline & Usar cama ortopédica & 2 & $11.76 \%$ \\
\hline & Posicionar a coluna ereta & 2 & $11.76 \%$ \\
\hline & Ficar de Pé & 1 & $5.88 \%$ \\
\hline & Flexionar os joelhos & 1 & $5.88 \%$ \\
\hline \multirow{9}{*}{$\begin{array}{c}\text { Fatores que } \\
\text { dificultam a } \\
\text { execução da } \\
\text { atividade de } \\
\text { movimentação de } \\
\text { pacientes no leito }\end{array}$} & Espaço Físico Inadequado & 10 & $58,82 \%$ \\
\hline & Grande carga fisica dispendida & 9 & $52.94 \%$ \\
\hline & Falta de Pessoal & 8 & $47.06 \%$ \\
\hline & Falta de Técnica Apropriada & 7 & $41.18 \%$ \\
\hline & Falta de Equipamentos & 3 & $17.64 \%$ \\
\hline & Equipamentos em más condições & 2 & $11.76 \%$ \\
\hline & Pacientes Pesados & 2 & $11.76 \%$ \\
\hline & Mobiliário inadequado & 1 & $5.88 \%$ \\
\hline & Pacientes dependentes & 1 & $5.88 \%$ \\
\hline
\end{tabular}

Podemos observar, através do quadro 1, que na opinião dos trabalhadores, os fatores que facilitam a execução da atividade de movimentação de paciente no leito estão relacionados a utilização da técnica apropriada, uso de instrumentos que facilitam a movimentação, tais como lençol e cama contendo regulagens e acessórios como trapézios para auxiliarem na movimentação, fazendo com que o paciente, quando permitir, contribua na movimentação. Foram ainda apontados como fatores facilitadores a adoção de algumas posições posturais e a observância de espaço suficiente para realização da atividade.

Quanto às dificuldades apontadas pelos trabalhadores o espaço fisico $(58,82 \%)$, a grande carga fisica dispendida $(52,94 \%)$, a falta de pessoal $(47,06 \%)$ e a falta de técnica apropriada $(41,18 \%)$ foram as mais citadas. 
Quando solicitados emitir sugestões sobre como movimentar pacientes no leito, quatro $(23,53 \%)$ trabalhadores apontaram que a utilização da posição da coluna ereta deveria ser adotada para a execução do procedimento e que o trabalhador de enfermagem não deve carregar muito peso.

BELLINI et al. (1996) acreditam que a utilização de recursos tecnológicos possam facilitar o trabalho, e que o esclarecimento e a capacitação do pessoal de enfermagem é fator decisivo para a diminuição do esforço físico dispendido para execução das tarefas de enfermagem. Ressaltam ainda que a formação e o treinamento em serviço poderiam ser recursos utilizados para se obter uma postura de trabalho em relação ao uso da mecânica corporal mais adequada pelos trabalhadores de enfermagem.

Quando questionados sobre materiais e/ou equipamentos que devem ser utilizados na técnica de movimentação de pacientes, oito trabalhadores $(47,06 \%)$ responderam que o material mais usado é o lençol de apoio, oito trabalhadores $(47,06 \%)$ não responderam e um trabalhador $(5,88 \%)$ disse ser o corpo do trabalhador o principal material na execução do procedimento. Quanto aos equipamentos destinados a facilitarem a execução de procedimentos de movimentação de pacientes, 13 trabalhadores $(76,47 \%)$ fizeram referência ao guincho de pacientes, três $(17,64 \%)$ à cama eletrônica, um $(5,88 \%)$ ao elevador de pacientes e quatro trabalhadores $(23,52 \%)$ não responderam. Os trabalhadores referiram a não disponibilidade de recursos tecnológicos para minimizar o esforço e o desgaste físico ocasionados pela execução da movimentação de pacientes acamados.

Quanto à técnica utilizada, a maioria dos trabalhadores demostraram desconhecimento da técnica correta.

Também evidenciaram a necessidade de utilização de recursos tecnológicos na clínica no momento em que foram indagados as sugestões para melhoria das condições existentes, nove $(52,94 \%)$ referiram a necessidade de aquisição de equipamentos facilitadores da execução de tarefas desgastantes, três $(17,65 \%)$ trabalhadores apontaram a necessidade do aumento do número de funcionários e cinco $(29,41 \%)$ trabalhadores não fizeram nenhuma sugestão.

Os resultados sugerem que além das atividades laborais executadas na unidade de ortopedia as outras atividades desenvolvidas, quer seja no segundo emprego ou no domicilio (tarefas doméstica), podem interferir na saúde destes profissionais, uma vez que na opinião destes trabalhadores, tais atividades requerem grande dispêndio de esforço físico e adoção de posturas inadequadas.

Ao analisarmos os dados obtidos através dos dados documentados através das filmagens, obtivemos os resultados apresentados no figura 3.

Figura 3- Dados obtidos através das gravações em vídeo tape do procedimento de movimentação de paciente no leito, realizado pelos 17 trabalhadores de enfermagem e analisadas de acordo com as posições assumidas pelos mesmos em relação às posições da coluna, braços e pernas. Ribeirão Preto, 1998.

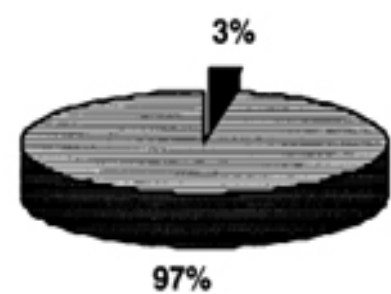

Através do total de 197,41 minutos de filmagem, referentes a 30 procedimentos filmados onde foi realizada a movimentação de pacientes acamados, durante o procedimento de banho no leito, foi observada a adoção em 5,46 minutos, $(2,8 \%$ do total observado) de boa postura, aquela por nós categorizada como o conjunto harmônico do dorso ereto, braços flexionados com cotovelo na altura da bancada ou a cinco centímetros dela e pernas flexionadas movimentando ou parada.

Em 191,95 minutos (97,2\% do total observado) foram adotadas pelos trabalhadores o conjunto de posturas desarmônicas, no que se refere às posições do conjunto dorso, braços e pernas e consideradas, portanto, má postura. No Anexo 2 são apresentados os dados obtidos em relação às posturas observadas.

\section{Boa Postura \\ EMá Postura}

Ou seja: da análise dos 30 procedimentos filmados encontramos que em 191,95 minutos $(97,2 \%$ do total de tempo de filmagem), os trabalhadores adotaram posições inadequadas à mecânica corporal e em 5,46 minutos (ou 2,8\% do tempo total observado) as posturas assumidas adequavam-se aos princípios da mecânica corporal e da ergonomia.

KNOPLICH (1989) descreve em seu estudo que a postura é definida como sendo um arranjo das partes do corpo e que se considera boa postura, o equilíbrio entre as estruturas de suporte do corpo, os músculos, os ossos, os quais protegem o mesmo contra uma agressão ou deformidade progressiva.

A má postura, é considerada por MARZIALE et al. (1991), como sendo aquela na qual existe uma falha de relacionamento das várias partes corporais, que 
induz a um aumento de agressão às estruturas de suporte e resulta em equilíbrio menos eficiente do corpo sobre suas bases. No mesmo estudo, descrevem que a postura submete-se às características anatômicas e fisiológicas do corpo humano, ligandose às limitações especificas do equilíbrio e obedecendo às leis da Física e Bio-Mecânica e, ainda, de outra parte, a mesma mantém estreito relacionamento com a atividade do indivíduo, podendo aumentar ou diminuir o esforço fisico de um trabalho.

BERNARDINA et al. (1995), em seu estudo concluem que os trabalhadores de enfermagem adotam em grande parte do tempo de suas funções, posições inadequadas, devendo-se alertá-los pois as mesmas poderão ocasionar-lhes problemas relacionados ao sistema músculo esquelético.

\section{CONCLUSÕES}

O estudo mostrou que a maioria dos trabalhadores de enfermagem têm consciência dos esforços e desgaste físicos necessários para a execução da atividade de movimentação de pacientes acamados e que encontram-se despreparados em relação ao uso de técnicas de movimentação corretas.

Devido a necessidade de muitos dos trabalhadores de enfermagem possuírem um segundo emprego, constatou-se aumento da sobrecarga de trabalho que é ainda maior quando o trabalhador realiza também atividades domésticas.

O uso da técnica adequada para movimentar o paciente $(52,94 \%)$, o uso do lençol $(35,29 \%)$ e o espaço adequado da enfermaria $(23,52 \%)$, foram citados pelos trabalhadores de enfermagem, como aspectos facilitadores da execução da atividade de movimentação de pacientes no leito.

Os trabalhadores apontaram os aspectos: inadequação de espaço $(58,82 \%)$, elevada carga fisica $(52,94 \%)$ e falta de pessoal $(47,06 \%)$ como as principais dificuldades encontradas na execução da movimentação de paciente no leito, corroborando com os achados da literatura, caracterizando essa atividade como penosa.

Quando solicitados a fazer sugestões, os trabalhadores destacaram a necessidade de aquisição de equipamentos facilitadores da execução de tarefas desgastantes e a necessidade do aumento do número de funcionários, como aspectos que minimizariam o desgaste fisico dispendido na execução das atividades laborais. Quanto à análise das posturas adotadas através das filmagens, os dados apontaram que os trabalhadores gastam $97 \%$ do tempo gasto para a execução dos procedimentos em posturas penosas, passiveis de causar danos ao sistema ósteo-muscular.

Alguns fatores foram referenciados pelos trabalhadores como indicadores da inadequação entre trabalho-trabalhador, no que se refere a sobrecarga física. O espaço fisico inadequado, a falta de equipamentos facilitadores do trabalho, e a presença de equipamentos em más condições de uso (camas com manivelas endurecidas e sem rodas ou com rodas e sem travas) o manuseio de grades e colchão d'água, foram apontados como fatores que dificultam a execução do trabalho de enfermagem e que acarretam desgaste fisico.

O presente estudo demostra que os trabalhadores de enfermagem adotam no exercício de suas atribuições profissionais posturas inadequadas à mecânica corporal as quais poderão acarretar a curto e longo prazo danos. Portanto necessitam ser orientados quanto aos riscos a que estão se sujeitando e os possíveis danos que poderão sofrer, bem como torna-se imprescindível o acesso destes profissionais a cursos de reciclagem e aprimoramento profissionais, procurando assim, diminuir o impacto de lesões ósteo-musculares e cervicodorsolombalgias nos mesmos.

\section{REFERÊNCIAS BIBLIOGRÁFICAS}

ALEXANDRE, N.M.C. Contribuição ao estudo das cervicodorsolombalgias em profissionais de enfermagem, Ribeirão Preto, 1993, 186 p. Tese (Doutorado), Escola de Enfermagem de Ribeirão Preto, Universidade de São Paulo.

ALEXANDRE,N.M.C. et. al. Aspectos ergonômicos e posturais em Centro de Material. Rev. Esc.Enf. USP, v. 26, n.1, p.87-94, 1992.

ALEXANDRE, N.M.C.; ANGERAMI, E.L.S. Estilo de vida e trabalho do pessoal de enfermagem e trabalho do pessoal de enfermagem e a ocorrência de cervicodorsolombalgias, Rev.Latino-Am.Enf., v. 3, n. 1, p.117-36, 1995.

ALEXANDRE, N.M.C.; ANGERAMI, E.L.S. Avaliação de determinados aspectos ergonômicos no transporte de pacientes. Rev. Bras. Saúde Ocupac., v. 21, n. 77, p.81-90, 1993.

ALEXANDRE,N.M.C. et al. Modelo de um curso de orientação sobre determinados apectos ergonômicos e posturais no trabalho do pessoal de enfermagem. Rev. Bras. Saúde Ocupac., n. 74, v. 19, 1991.

AQUINO, E.M.L. et al. Saúde e trabalho de mulheres profissionais de enfermagem em um hospital público de Salvador, Bahia. Rev. Bras. Enf., v. 46, n. 3/4, p. 245-7, 1993.

BELLINI,C. et al. Utilização de recursos tecnológicos como agente facilitador do trabalho de enfermagem. Rev. LatinoAm. Enf., v. 4, n. 2, p.101-11, 1996.

BERNARDINA, L.D. et al. Postura corporal adotada pelos membros da equipe de enfermagem durante o procedimento de colheita de sangue, administração de medicação endovenosa e soroterapia. Rev. Esc. Enf. USP, v.29, n.3, p.317-30, 1995.

CONSElho fEDERAL DE ENFERMAGEM. Código de Ética. Profissionais de enfermagem, Rio de Janeiro, 1993. 
CONSELHO FEDERAL DE ENFERMAGEM. Exercicio de enfermagem nas instituições de saúde do Brasil 1982/1983: força de trabalho em enfermagem. Rio de Janeiro, 1985.

CUST, G. et al. The prevalence of low back pain in nurses. Int.Nurs.Rev., v.19, n.2, p.169-79, 1972.

ENGELS, J.A et. al. Physical Work load and its assessment among the nursing staff in nursing homes. J. Occup. Med., v. 36, n.3, p.338-45, 1994

ESTRYN-BEHAR, M. Caractéirstiques du personnel hospitalier et aménagement des conditions de travail: Mémorie pour le diplome dérgonomiste CNAM Départament des Sciences de L'Homme au Travail, oct., 1980.

JENSEN, R. Disabling back injuries among nursing personal: research needes and justification. Res. Nurs.Health, v.10, n.1, p.29-38, 1987.

KOZIER, B.; ERB, G.; OLIVERI, R. Fundamentals of nursing: concepts process and practice. Massachusetts, 1991, p.882-937, 1991.
KNOPLICH, J. Endirite as costas. São Paulo, IBRASA, 1989.

MARZIALE, M.H.P.et al. A postura corporal adotada pela enfermeira durante a execução de seu trabalho. Rev. Bras. Saúde Ocupac., v.19, n. 73, p.19-24, 1991.

MARZIALE, M.H.P. Condições ergonômicas da situação de trabalho do pessoal de enfermagem, em uma unidade de internação hospitalar, Ribeirão Preto, 1995, 186p., Tese (Doutorado), Escola de Enfermagem de Ribeirão Preto, Universidade de São Paulo.

REIS,I.N. Doenças ocupacionais: estudo retrospectivo em unidades hospitalares do DF. IL F. A. Publ. Cient. v. 1, n. 2, 113-22, 1986

SORENSEN, K.C.; LUCKMANN, J. Basic nursing: a psychophysilogic approach, Philadelphia, 1994, p.730-846.

THEUREAU, J. Equilibre ou fatigue par le travail. Paris, ESF, 1980, p. $141-151$.

\section{ANEXO 1}

Impressões do trabalhador de enfermagem sobre a atividade de movimentação de pacientes no leito.

\section{I- Identificação:}

Idade: anos.

Sexo: 1. Feminino

Estado Civil: 1. Solteiro

Função: 1. Enfermeiro

Local de trabalho: 1. Ortopedia Ala Feminina

Horário de trabalho: 1. Manhã

Turno: 1. Fixo

II- Informações relativas à atividade profissional:

1-A quanto tempo, exerce a função atual, nesta unidade?

2. Masculino

2. Casado 3. Outros:

2. Técnico de Enfermagem 3. Auxiliar de Enfermagem

2. Ortopedia Ala Masculina

2. Tarde 3. Noite

2. Alternante

2-Atualmente possui outro emprego ou ocupação? anos meses.

Caso a resposta for negativa vá para a pergunta 3, se for afirmativa responda:

2.1- Qual a função que possui?

2.2- Qual o local de trabalho?

2.3- Para a execução das atividades que você executa nesta outra função é necessário:

a- Empregar esforço físico:

1. Sim 2. Não

b- Inclinar a coluna:

1. Sim 2. Não

c- Carregar peso:

1. Sim

2. Não

d- Torcer a coluna:

1. Sim

2. Não

e- Estirar a coluna:

1. Sim

2. Não

f- Flexionar várias vezes a coluna:

1. Sim 2. Não

g- Outras necessidades:

1. Sim 2. Não

$$
\text { Quais? }
$$

3-Você realiza alguma (s) atividade (s) doméstica?
1. Sim
2. Não

Caso a resposta seja negativa, vá para pergunta 4, se a resposta for afirmativa responda:

a- Empregar esforço físico:

1. Sim 2. Não

b- Inclinar a coluna:

1. Sim

2. Não

c- Carregar peso:

1. Sim

2. Não

d- Torcer a coluna:

1. Sim

2. Não

e- Estirar a coluna:

1. Sim

2. Não

f- Flexionar várias vezes a coluna:

1. Sim

2. Não

g- Outras necessidades:

1. Sim

2. Não Quais? 
4-Relate quais as facilidades encontradas na execução da atividade de movimentação de paciente no leito em relação aos aspectos abaixo descritos e porque ocorrem:

a Técnica:

b. Material e/ou equipamento:

c. Mobiliário:

d. Espaço:

e. Carga fisica:

f. Posicionamento do corpo:

g. Outros (descrever):

5-Relate quais as facilidades encontradas na execução da atividade de transferência de paciente do leito para a cadeira ou maca em relação aos aspectos abaixo descritos e porque eles ocorrem.

Técnica:

b. Material e/ou equipamento:

c. Mobiliário:

d. Espaço:

e. Carga física:

f. Posicionamento do corpo:

g. Outros (descrever):

6-Relate quais as dificuldades encontradas na execução da atividade de movimentação de paciente no leito em relação aos aspectos abaixo descritos e porque eles ocorrem. Técnica:

b. Material e/ou equipamento:

c. Mobiliário:

d. Espaço:

e. Carga física:

f. Posicionamento do corpo:

g. Outros (descrever):

7-Relate quais as dificuldades encontradas na execução da atividade de transferência de paciente do leito para a cadeira ou maca em relação aos aspectos abaixo descritos e porque eles ocorrem.

Técnica:

b. Material e/ou equipamento:

c. Mobiliário:

d. Espaço:

e. Carga física:

f. Posicionamento do corpo:

g. Outros (descrever):

\section{Ill- Informações relativas à saúde:}

8-Possuí algum problema de saúde?

() Sim ( )Não

Caso a resposta for afirmativa especificar:

Qual (is) o (s) problema (s)?

Desde quando o (s) possuí?

Qual (is) o(s) diagnóstico (s)?

$\mathrm{O}$ que atribui a causa do problema?

9-Já foi afastado do serviço devido a problemas de saúde relacionados ao sistema músculo esquelético (Ex.: coluna)?
( ) Sim
( ) Não

Se a resposta for afirmativa especificar:

Quando?

Qual (is) o (s) motivo (s)?

Qual o número de dias de afastamento do serviço?

\section{IV- Sugestões:}

Você poderia colaborar fazendo sugestões em relação a :

1-Qual a postura corporal em relação à posição da coluna, braços e pernas que o trabalhador de enfermagem deve assumir durante a execução da atividade de movimentação de paciente.

2. Quais os materiais que devem ser utilizados na movimentação de paciente?

3. Quais os equipamentos que devem ser utilizados na movimentação de paciente?

4. Descreva a técnica que deve ser utilizada para movimentar o paciente?

5. Possui alguma outra ou outras sugestões que deseje fazer? 


\section{ANEXO 2}

Posições assumidas pelos trabalhadores de enfermagem durante a execução dos procedimentos de movimentação de pacientes no leito, ao longo de 197,41 minutos de filmagens.

\begin{tabular}{|c|c|c|c|}
\hline Posição $\mathbf{n}^{\circ}$ : & Posições Assumidas Pelos trabalhadores & $\begin{array}{c}\text { Total de tempo } \\
\text { (segundos) }\end{array}$ & Porcentagem \\
\hline 1 & Inclinado/cotovelo abaixo da bancada/extensão & 6377 & $53,76 \%$ \\
\hline 2 & Ereto/cotovelo abaixo da bancada/extensão & 1205 & $10,15 \%$ \\
\hline 3 & Ereto/cotovelo acima da bancada/extensão & 971 & $8,19 \%$ \\
\hline 4 & Ereto/cotovelo abaixo da bancada/andando & 940 & $7,93 \%$ \\
\hline 5 & Torcido/cotovelo abaixo da bancada/extensão & 852 & $7,18 \%$ \\
\hline 6 & Inclinado/cotovelo acima da bancada extensão & 271 & $2,28 \%$ \\
\hline 7 & Ereto/cotovelo na altura da bancada/andando & 263 & $2,22 \%$ \\
\hline 8 & Ereto/cotovelo na altura da bancad/extensão & 310 & $2,61 \%$ \\
\hline 9 & Inclinado/cotovelo abaixo da bancada/andando & 186 & $1,57 \%$ \\
\hline 10 & Ereto/cotovelo acima da bancada andando & 145 & $1,22 \%$ \\
\hline 11 & Estirado/cotovelo acima da bancada/extensão & 41 & $0,34 \%$ \\
\hline 12 & Inclinado/cotovelo na altura da bancada/flexão & 38 & $0.32 \%$ \\
\hline 13 & Inclinado/cotovelo na altura da bancad/extensão & 33 & $0,28 \%$ \\
\hline 14 & Inclinado/cotovelo abaixo da bancada/flexão & 31 & 0.26 \\
\hline 15 & Ereto/extensão/extensão & 28 & $0,48 \%$ \\
\hline 16 & Ereto/cotovelo na altura da bancad/flexão & 28 & $0,24 \%$ \\
\hline 17 & Torcido/cotovelo abaixo da bancada/flexão & 28 & $0,24 \%$ \\
\hline 18 & Inclinado/cotovelo na altura da & 18 & $0,15 \%$ \\
\hline 19 & Ereto/extensão andando & 15 & $0,13 \%$ \\
\hline 20 & Inclinado/cotovelo acima da bancada/andando & 15 & $0,13 \%$ \\
\hline 21 & Ereto/cotovelo abaixo da bancada/flexão & 14 & $0,12 \%$ \\
\hline 22 & Inclinado/extensão/extensão & 14 & $0,12 \%$ \\
\hline 23 & Torcido/cotovelo acima da bancada/extensão & 14 & $0,12 \%$ \\
\hline 24 & Estirado/cotovelo abaixo da bancada/extensão & 12 & $0,10 \%$ \\
\hline 25 & Torcido/cotovelo na altura da & 10 & $0,08 \%$ \\
\hline 26 & Torcido/cotovelo acima da bancada/andando & 2 & $0,02 \%$ \\
\hline
\end{tabular}

